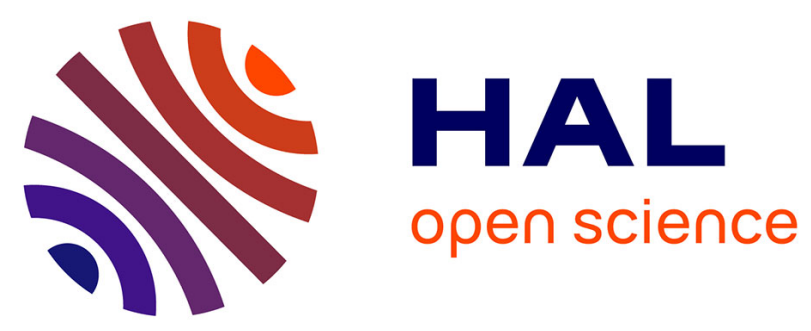

\title{
Damage Mechanisms in Medium-Voltage Insulating Polymers under Hemispherical-Plane Electrodes
}

\author{
J. Fernandez, D. Long, P. Sotta, J-F. Larche, A. Allais, D. Charrier, R.
} Guffond, R. Fulchiron, B. Dalbe, M. Tauban, et al.

\section{- To cite this version:}

J. Fernandez, D. Long, P. Sotta, J-F. Larche, A. Allais, et al.. Damage Mechanisms in Medium-Voltage Insulating Polymers under Hemispherical-Plane Electrodes. IEEE 3rd International Conference on Dielectrics (ICD 2020), Jul 2020, Valence (virtuel), Spain. pp.33-36, 10.1109/ICD46958.2020.9341853 . hal-03450783

\section{HAL Id: hal-03450783 \\ https://hal.science/hal-03450783}

Submitted on 4 Jan 2022

HAL is a multi-disciplinary open access archive for the deposit and dissemination of scientific research documents, whether they are published or not. The documents may come from teaching and research institutions in France or abroad, or from public or private research centers.
L'archive ouverte pluridisciplinaire HAL, est destinée au dépôt et à la diffusion de documents scientifiques de niveau recherche, publiés ou non, émanant des établissements d'enseignement et de recherche français ou étrangers, des laboratoires publics ou privés. 


\section{Damage Mechanisms in Medium-Voltage Insulating Polymer Materials under Sphere-Plane Electrodes}

\author{
J. Fernandez, D. Long, P. Sotta \\ Laboratoire Polymères et \\ Matériaux Avancés \\ 87 avenue des Frères Perret \\ 69192 Saint-Fons, France \\ julien.fernandez@solvay.com
}

\author{
J-F. Larché, A. Allais, \\ D. Charrier, R. \\ Guffond, B. Dalbe \\ Nexans Research Center \\ 18 rue Lortet \\ 69007 Lyon, France
}

\author{
R. Fulchiron \\ Ingénierie des Matériaux \\ Polymères, Université \\ Claude Bernard Lyon 1 \\ 15 boulevard Latarjet \\ 69622 Villeurbanne, France
}

\author{
M. Tauban \\ Materials Design and \\ Development Lab (M2D), \\ Solvay RICL \\ 87 avenue des Frères \\ Perret \\ 69192 Saint-Fons, France
}

\begin{abstract}
Controlling the lifetime of insulating materials is required to insure reliability of insulation systems for Medium Voltage (MV) and High Voltage (HV) cables. The aging behavior of Low Density (LDPE) and Cross-Linked Polyethylene (XLPE) under MV-AC thermo-electric stress is studied in the sphereplane geometry in air to identify degradation mechanisms associated to Corona Discharges (CDs) and their impact on insulation lifetime. Time-to-breakdown values are measured under different applied electric fields. Additionally, XLPE samples are aged to different ageing steps. Then, the samples are analyzed by scanning electron microscopy and infrared spectroscopy to monitor progressive damage during ageing.
\end{abstract}

Keywords—MV-AC; XLPE; surface discharges; lifetime; ageing;

\section{INTRODUCTION}

Electrical aging and breakdown of polymeric insulators have been studied for over thirty years [1]. In particular the respective roles of bulk damaging of the polymeric material and of Partial Discharges (PDs) within microscopic cavities, have been increasingly studied. PD inception and induced ageing scenarios have been depicted in the literature [2-6]. A generally accepted scenario is that continuous bombardment of the dielectric surface by active species from the discharge results in progressive erosion of the surface, followed by localized chemical modification and field enhancement, which causes pit formation. These microstructural changes eventually lead to treeing and insulation failure [7].

Gamez-Garcia et al. have studied chemical reactions at XLPE surfaces subjected to discharges in controlled atmospheres [8] and also studied the impact of temperature up to $160^{\circ} \mathrm{C}$ [9]. More recently, Leon-Garzon et al. have studied the effects of corona discharges over polymeric slabs and characterized the modifications of the surfaces [10]. These studies show that chemical reactions occurring in solid dielectrics submitted to PDs produce gaseous, liquid and solid by-products, which concentration and nature depend on the ageing conditions.

Yet, the effect of PDs on the insulator lifetime and their role on the acceleration of ageing still need to be elucidated. In this work, Polyethylene (PE) based materials are aged under MVAC $(50 \mathrm{~Hz})$ stresses using a sphere-plane electrode in air, in order to trigger Corona Discharges. Time-to-breakdown values are recorded on different samples and at different voltages. The correlation between discharge-induced failure mechanisms and morphological changes occurring at different steps of the polymer lifetime is discussed.

\section{EXPERIMENTAL PROCEDURE}

\section{A. Materials and Sample Preparation}

Polymer films are prepared from LDPE pellets by compression molding. XLPE samples are cross-linked with Tert-Butyl Cumyl peroxide (TBCP). An anti-oxidant (Irganox 1035) is added to all grades The formulations are described in Table I. The films are $100 \pm 10 \mu \mathrm{m}$ thick as controlled with a scotch tape with standard thickness during compression molding. Samples for endurance tests are disks of $30 \mathrm{~mm}$ in diameter punched from polymer films.

TABLE I.

Composition of the Prepared Polymer Films

\begin{tabular}{|c|c|c|c|c|}
\hline \multirow{2}{*}{ Components } & \multicolumn{4}{|c|}{ Samples } \\
\cline { 2 - 5 } & LDPE & XLPE A & XLPE B & XLPE C \\
\hline Anti-oxidant & $0.3 \mathrm{phr}^{\mathrm{a}}$ & $0.3 \mathrm{phr}^{\mathrm{a}}$ & $0.3 \mathrm{phr}^{\mathrm{a}}$ & $0.3 \mathrm{phr}^{\mathrm{a}}$ \\
\hline TBCP & None & $0.5 \mathrm{phr}^{\mathrm{a}}$ & $1.0 \mathrm{phr}^{\mathrm{a}}$ & $1.5 \mathrm{phr}^{\mathrm{a}}$ \\
\hline
\end{tabular}

\section{B. Experimental setup}

The experimental setup for ageing tests consists of a set of sphere-plane electrodes as described in Fig. 1. High-voltage electrodes are stainless-steel rods with a sphere tip $4 \mathrm{~mm}$ in diameter which are mirror-polished to ensure clean contact. The tip is placed in contact with samples surface. The ground electrode is made of a stainless-steel plate covered by aluminum foil. A temperature probe is used to control the testing temperature at the surface of the ground electrode.

\section{Ageing Conditions}

In a specially designed cell, ten electrodes deliver up to 9.9 $\mathrm{kV} \mathrm{AC}(50 \mathrm{~Hz})$ on ten test samples. The same voltage is applied to the ten samples and is maintained constant until breakdown of all samples. Time-to-breakdown values as a function of applied stress are recorded independently for the ten samples. The whole system is placed in an oven at the testing temperature $90^{\circ} \mathrm{C}$. Accelerated endurance tests are performed under stresses between 15 and $60 \mathrm{kV} / \mathrm{mm}$. This 
corresponds to stresses 6 to 12 times higher than those used in medium voltage cables [11].

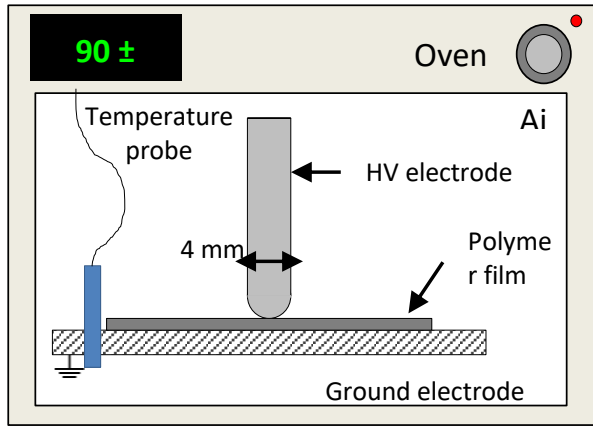

Fig. 1. Experimental setup for endurance tests under MVAC voltage.

Subsequently to breakdown tests, XLPE C samples are being aged at $90^{\circ} \mathrm{C}$ under $28 \mathrm{kV} / \mathrm{mm}$ for durations corresponding to different fractions of the breakdown time, in order to follow the evolution of the insulator properties at different stages of their lifetime.

\section{Characterization Methods}

XLPE C samples are characterized at different ageing steps to monitor progressive degradation along the lifetime. Optical (OM) and Scanning Electron Microscopy (SEM) are used to investigate microstructural changes, while Fourier Transform Infrared Spectroscopy (FTIR) is used to investigate chemical modifications.

\section{E. Statistical Analysis}

Time-to-breakdown data are fitted using a two-parameter cumulative Weibull function of the time-to-breakdown $(t)$ defined by Equation (1):

$$
F(t ; \alpha, \beta)=1-\exp \left\{-(t / \alpha)^{\beta}\right\}
$$

The scale parameter $\alpha$ is the time after which $63.2 \%$ of the samples failed, and is identified to the characteristic insulation lifetime $\tau_{\mathrm{c}}$ (in minutes) of the sample population at the given applied stress (voltage), while the shape parameter $\beta$ refers to the data dispersion. For practical reasons, ten samples only are used for the Weibull distribution, which is lower than the 20 samples usually recommended [ ]. The obtained data are fitted using an Inverse Power Law [1] as defined by Equation (2):

$$
\tau_{c}=A \times V^{-n}
$$

where $V$ is the applied AC stress, and $A$ and $n$ are constants. The parameter $n$ is known as the voltage endurance coefficient (VEC) [13], and describes the decrease of the insulation lifetime as the electrical stress increases.

\section{RESULTS AND DISCUSSION}

\section{A. Endurance Tests of PE based samples}

Table II shows the Weibull parameters of endurance tests performed on the four PE based materials under three different voltages. Fig. 2 shows the characteristic lifetimes of the different materials as a function of the applied voltage. The VEC values obtained by fitting the data of Fig. 2 are also reported in Table II.

The trends of insulation lifetime are similar to literature data $[13,14]$. Under a given applied voltage, the lifetime increases when increasing the peroxide amount. Cross-linking thus increases the endurance of polyethylene at medium electrical stresses. A possible reason is that cross-linking prevents polyethylene from creeping, which would increase the macroscopic electrical stress during ageing at $90^{\circ} \mathrm{C}$.

The shape parameter $\beta$ seems to be independent of the applied voltage or peroxide amount.

The fitted VEC values are close to $n=2$ in all materials. This is in the range of values reported for PD breakdown on polymeric films (2-5) [14], supporting the hypothesis of discharge-associated mechanisms on the surface of samples in this sphere-plane electrode geometry.

Preliminary tests at lower stress fields resulted in larger $n$ values, suggesting a different failure mechanism which may not be associated to surface discharges.

TABLE II

\begin{tabular}{|c|c|c|c|c|c|c|c|}
\hline & \multicolumn{3}{|l|}{ LDPE } & & \multicolumn{3}{|c|}{ XLPE A } \\
\hline $\begin{array}{l}\text { Voltage } \\
\left(\mathrm{V}_{\text {Max }}\right)\end{array}$ & $\begin{array}{l}\alpha \\
(\min )\end{array}$ & $\beta$ & VEC & $\begin{array}{l}\text { Voltage } \\
\left(\mathrm{V}_{\text {Max }}\right)\end{array}$ & $\begin{array}{l}\alpha \\
(\min )\end{array}$ & $\beta$ & VEC \\
\hline 1414 & 4270 & 5.58 & \multirow{3}{*}{1.89} & 1414 & 4825 & 8.52 & \multirow{3}{*}{1.84} \\
\hline 2828 & 1431 & 4.22 & & 2828 & 1736 & 4.88 & \\
\hline \multirow[t]{2}{*}{4243} & 533 & 5.67 & & 4243 & 635 & 3.07 & \\
\hline & \multicolumn{3}{|c|}{ XLPE B } & & \multicolumn{3}{|c|}{ XLPE C } \\
\hline $\begin{array}{l}\text { Voltage } \\
\left(\mathrm{V}_{\text {Max }}\right)\end{array}$ & $\begin{array}{l}\alpha \\
(\min )\end{array}$ & $\beta$ & VEC & $\begin{array}{l}\text { Voltage } \\
\left(\mathrm{V}_{\text {Max }}\right)\end{array}$ & $\begin{array}{l}\alpha \\
(\min )\end{array}$ & $\beta$ & VEC \\
\hline 1414 & 6252 & 6.87 & \multirow{3}{*}{1.95} & 1697 & 5733 & 4.29 & \multirow{3}{*}{2.11} \\
\hline 2828 & 1666 & 4.91 & & 2828 & 1674 & 3.70 & \\
\hline 4385 & 653 & 8.04 & & 4385 & 803 & 13.4 & \\
\hline
\end{tabular}

Weibull and Lifetime Parameters of Endurance Tests

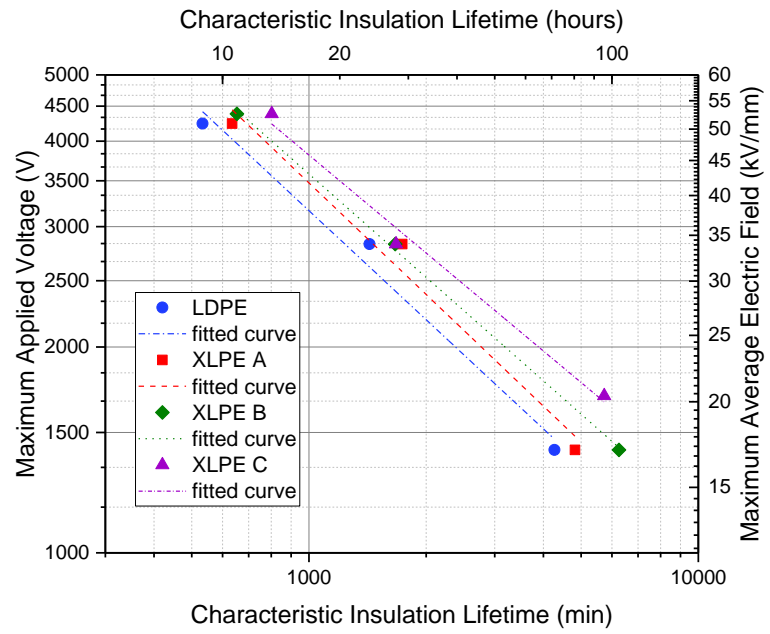

Fig. 2. Characteristic lifetime of PE-based insulators under $50 \mathrm{~Hz}$ AC voltage as a function of the applied voltage at $90^{\circ} \mathrm{C}$. 


\section{B. Ageing of XLPE samples}

XLPE C samples were then aged at $2.3 \mathrm{kV}(\sim 28 \mathrm{kV} / \mathrm{mm})$ and $90^{\circ} \mathrm{C}$ for ageing times $30,120,360,900,1440,2220$, and 2880 minutes, corresponding roughly to $1,4,12.5,31,50,77$ and $99 \%$ of the expected lifetime, which is about 2900 minutes at this voltage.

The microstructure evolution of aged XLPE samples was characterized by OM and SEM. Fig. 3 shows the of XLPE C surface after breakdown at $4.4 \mathrm{kV}$. A grey disk surrounded by a ring pattern, centered on the contact point of the spherical electrode visible near the center of the image, is observed. This disk corresponds to the aged region, while the unaged region is the surrounding transparent material.

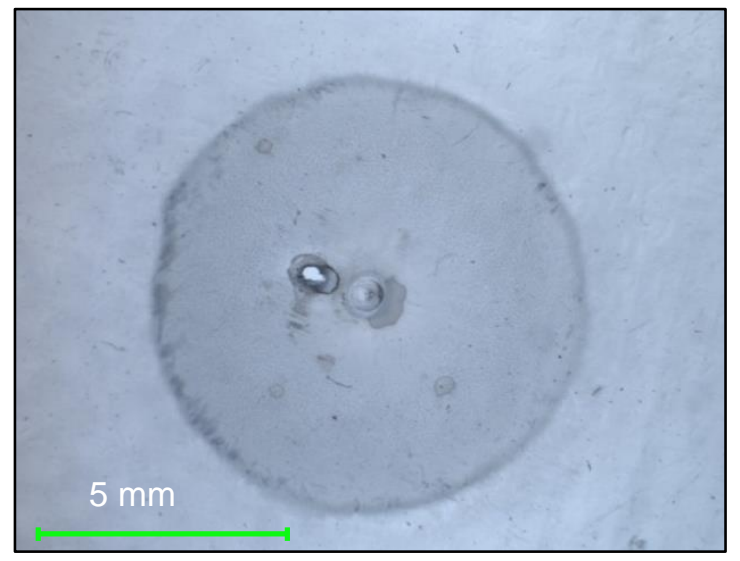

Fig. 3. Image of XLPE C surface after breakdown at $1.7 \mathrm{kV}$. Optical Microscopy (bright-field) (8X).

SEM characterization of the aged surface confirms the presence of a microstructure with a gradient along the radius of the ageing pattern. Fig. 4 shows the surface microstructure of an aged sample after 2880 minutes under $2.3 \mathrm{kV}$ at the frontier between the unaged (left) and aged regions (right), 2.5 $\mathrm{mm}$ away from the contact point. Pits and craters are observed in the aged region, forming channels about $1 \mu \mathrm{m}$ wide. They fade away in the unaged region.

Similar microstructures are observed in other aged samples at the frontier between aged and unaged regions. Closer to the center, the microstructure evolves with ageing time. Fig. 5 shows SEM images of samples aged for 120, 360, 1440 and 2880 minutes, $1 \mathrm{~mm}$ away from the contact point. Pits and craters are observed after 120 minutes (5.A), similar to those observed at the periphery of the aged region. On increasing the ageing time (360 minutes, 5.B), the surface roughness increases, channels erode progressively, the number of pits decreases and granular-like solid by-products appear. Liquid and solid byproducts have been reported on XLPE and epoxy surfaces subject to discharges [5]. It is generally admitted that pits are indicative of discharge-induced degradation as they are due to continuous bombardment of the surface by active species, that they correspond to an advanced stage of ageing and lead to treeing and final breakdown. This mechanism may describe ageing in the vicinity of cavities embedded in cable insulators, or near a metallic protrusion in the presence of air.

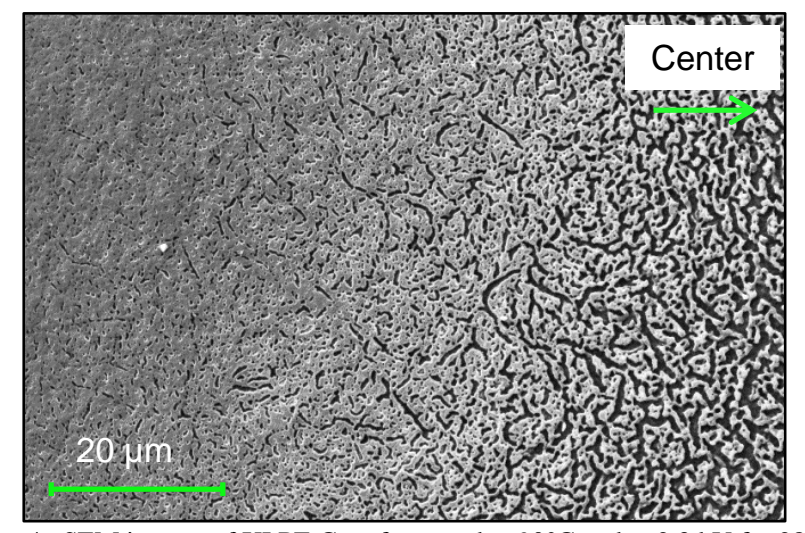

Fig. 4. SEM images of XLPE C surface aged at $90^{\circ} \mathrm{C}$ and at $2.3 \mathrm{kV}$ for 2880 minutes. Observed microstructure at the frontier between unaged (left) and aged region (right), $2.5 \mathrm{~mm}$ away from the center of the degraded surface.

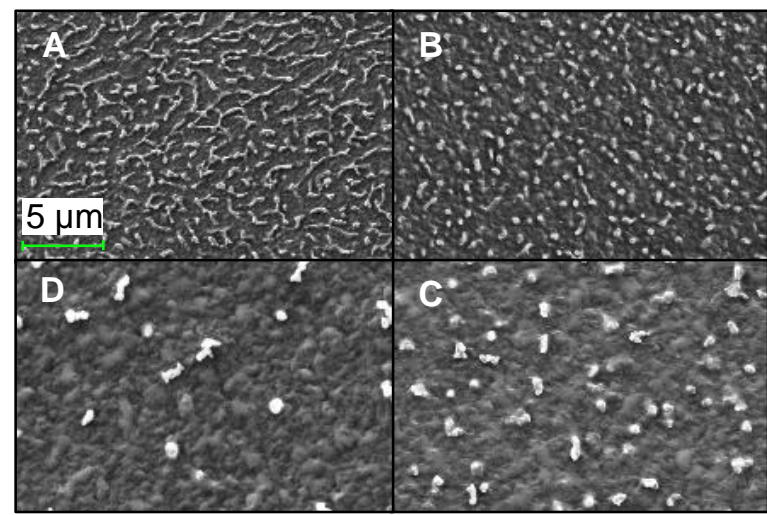

Fig. 5. SEM images of XLPE C surface aged at $90^{\circ} \mathrm{C}$ and at $2.3 \mathrm{kV}$ for 120 (A), 360 (B), 1440 (C) and 2880 minutes (D). Observed microstructure $1 \mathrm{~mm}$ away from the center of the degraded surface.

The samples were characterized by FTIR to correlate this microstructure evolution with chemical ageing. Fig. 6 shows FTIR spectra of XLPE samples at different ageing time, in the range 1850 to $1600 \mathrm{~cm}^{-1}$. The spectra were normalized with respect to a reference absorption peak near $2019 \mathrm{~cm}^{-1}$ commonly used in the literature, associated to polyethylene and proportional to the film thickness $[15,16]$.

Two peaks associated to carbonyl groups are observed in the $1850-1600 \mathrm{~cm}^{-1}$ range [17], a broad one at $1736 \mathrm{~cm}^{-1}$ (esters or aldehydes), one at $1714 \mathrm{~cm}^{-1}$ (ketones). These compounds are already present in the unaged XLPE, due to the presence of residual cross-linking by-products. Additional XLPE C samples were thermally aged (at $90^{\circ} \mathrm{C}$ without voltage) to discriminate chemical changes associated to thermo-electrical ageing and thermal ageing only.

Fig. 7 shows the evolution of the maxima of the two peaks associated to carbonyl groups. The absorbance of these carbonyl groups increases with ageing time under electrical stress and thermal ageing. The increase is larger for the films submitted to electrical stress. Similar results have been reported in PE and XLPE submitted to corona discharges in air [8-10] and artificial weathering [17]. This result is thus the signature of discharged-induced ageing at the polymer surface. 


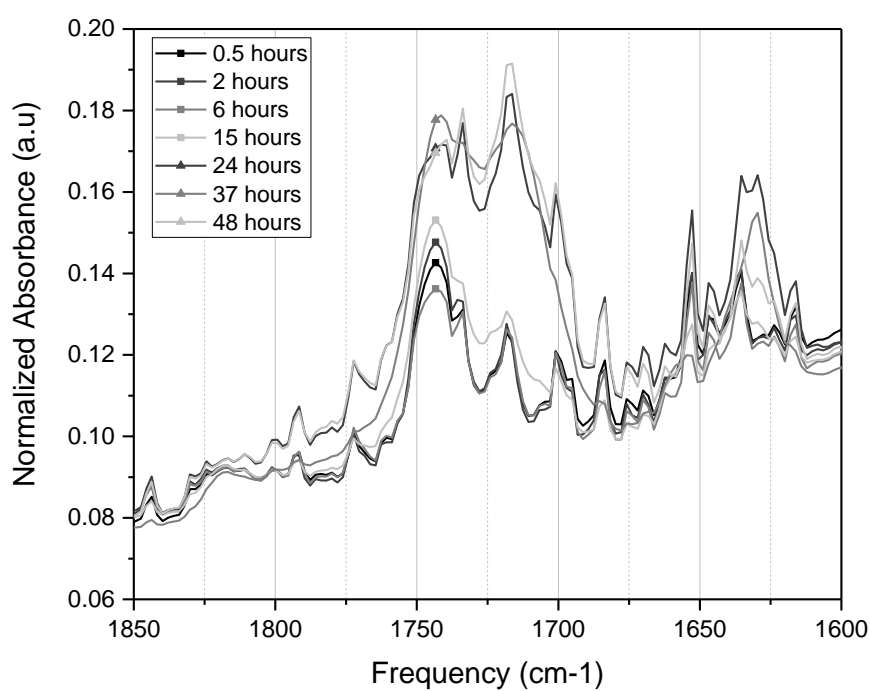

Fig. 6. Normalized FTIR spectra XLPE samples aged at $90^{\circ} \mathrm{C}$ and under 2.3 $\mathrm{kV}$ for increasing ageing time. Zoom on $1850-1600 \mathrm{~cm}^{-1}$ region.

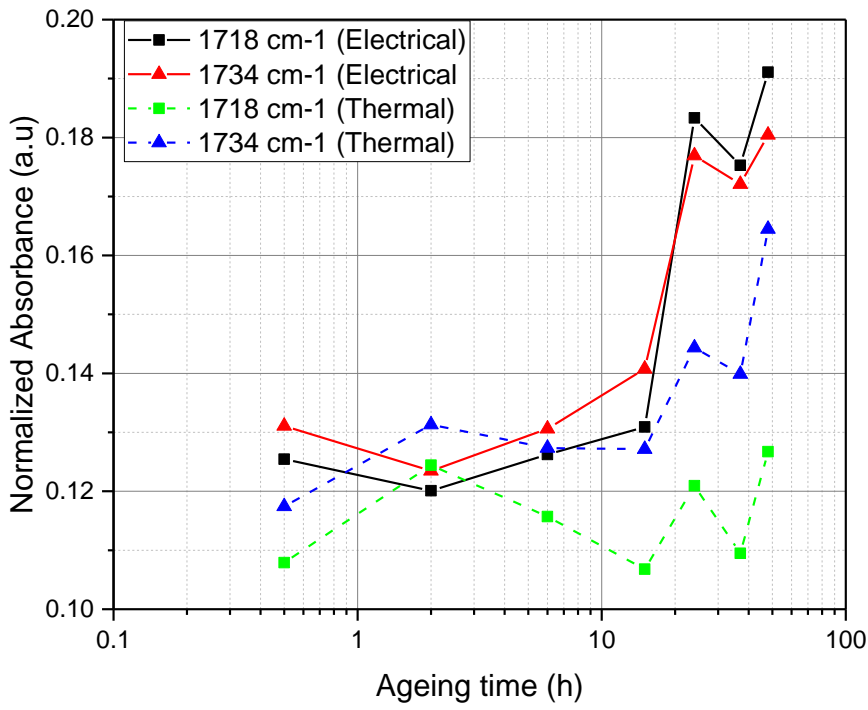

Fig. 7. Evolution of the maxima of carbonyl peaks in aged XLPE spectra as a function of ageing time, in electrically and thermally aged samples.

\section{CONCLUSION AND PERSPECTIVES}

From the present experimental results the following conclusions can be drawn:

- Endurance tests performed on LDPE and XLPE samples under a sphere-plane electrode in air show that increasing the peroxide amount increases the lifetime performance of the materials. Fitted VEC values support a breakdown mechanism associated to discharges in air.

- As shown by FTIR the concentration of carbonyl groups increases with ageing time.

- The ageing pattern on the aged XLPE surface can be divided in different sub regions. Granular-like byproducts are found near the electrode-polymer contact, while pitting is observed away from the contact. As the number of pits decreases with time and give way to bigger gaps, the surface roughness of the sample increases and final breakdown of the XLPE samples is thought to occur due to treeing.

At the time of writing this paper, current-voltage characteristics are measured on aged XLPE samples to assess the effect of ageing on charge injection and conduction. Luminescence measurements are planned to monitor the impact of ageing on the electronic states of the polymer.

\section{REFERENCES}

[1] L. A. Dissado and J. C. Fothergill, Electrical Degradation and Breakdown in Polymers. London, UK:Peter Peregrinus Ltd., 1992.

[2] G. C. Crichton, P. W. Karlsson, and A. Pedersen, "Partial discharges in ellipsoidal and spheroidal voids," IEEE Transactions on Electrical Insulation, vol. 24, no. 2, pp. 335-342, Apr. 1989.

[3] P. H. F. Morshuis, "Partial Discharge Mechanisms - Mechanisms leading to breakdown, analysed by fast electrical and optical measurements," PhD Thesis, Technische Universiteit Delft, Delft, 1993.

[4] K. Temmen, "Evaluation of surface changes in flat cavities due to ageing by means of phase-angle resolved partial discharge measurement", J. Phys. D: Appl. Phys. 33, pp. 603-608, 2000.

[5] A. R. Leon-Garzon, F. Manenti, G. Dotelli, A. Villa, L. Barbieri, and M. Gondola, "Lumped mechanism for polymeric dielectric degradation under high electrical fields," Chemical Engineering Transactions, pp. 1711-1716, 2015.

[6] C. Cavallotti, A. R. Leon-Garzon, G. Dotelli, A. Villa, L. Barbieri, and M. Gondola, "Thermodynamic analysis of the degradation of polyethylene subjected to internal partial discharges," Chemical Engineering Science, vol. 180, pp. 1-10, Apr. 2018.

[7] Morshuis, P.H.F., "Degradation of solid dielectrics due to internal partial discharge: some thoughts on progress made and where to go now", IEEE Transactions on Dielectrics and Electrical Insulation 12, pp. 905-913, 2005

[8] M. Gamez Garcia, R. Bartnikas and M.R. Wertheimer, "Synthesis reactions involving XLPE subjected to partial discharges", IEEE Trans. Electr. Insul., Vol. 22, pp. 199 - 205, 1987.

[9] M. Gamez-Garcia, R. Bartnikas, and M. R. Wertheimer, "Modification of XLPE exposed to partial discharges at elevated temperature," IEEE Trans. Elect. Insul., vol. 25, no. 4, pp. 688-692, Aug. 1990.

[10] Leon-Garzon et al., "Experimental Characterization of Polymer Surfaces Subject to Corona Discharges in Controlled Atmospheres," Polymers, vol. 11 , no. 10, p. 1646, Oct. 2019.

[11] O. E. Gouda, A. A. ElFarskoury, A. R. Elsinnary, and A. A. Farag, "Investigating the effect of cavity size within medium-voltage power cable on partial discharge behavior," IET Generation, Transmission \& Distribution, vol. 12, no. 5, pp. 1190-1197, Mar. 2018.

[12] D. Jang and S. Park, "Evaluation of Electrical Tree Degradation in Cross-Linked Polyethylene Cable Using Weibull Process of Propagation Time," Energies, vol. 10, no. 11, p. 1789, Nov. 2017.

[13] L. Simoni, "A General Approach to the Endurance of Electrical Insulation Under Temperature and Voltage," IEEE Transactions on Electrical Insulation, vol. 16, no. 4, pp. 277-289, 1981.

[14] N. Yoshimura, M. S. A. A. Hammam, M. Nishida, and F. Noto, "Effect of microvoids on V-t characteristics and tree growth in crosslinked polyethylene," in Conference on Electrical Insulation \& Dielectric Phenomena - Annual Report 1978, Pocono Manor, PA, USA, pp. 342351,1978 .

[15] K. Möller, T. Gevert, and A. Holmström, "Examination of a low density polyethylene (LDPE) film after 15 years of service as an air and water vapour barrier," Polymer Degradation and Stability, vol. 73, no. 1, pp. 69-74, Jan. 2001

[16] $\mathrm{D}$. Li and T. J. Person, "Performance evaluation of XLPE materials for $90^{\circ} \mathrm{C}$ HVDC applications," in 2017 IEEE Conference on Electrical Insulation and Dielectric Phenomenon (CEIDP), Fort Worth, TX, 2017, pp. 661-633.

[17] J. V. Gulmine and L. Akcelrud, "FTIR characterization of aged XLPE," Polymer Testing, vol. 25, no. 7, pp. 932-942, Oct. 2006. 